\title{
Compensation of voltage flicker by using facts devices
}

\author{
Jyothilal Nayak Bharothu, K Lalitha \\ Sri Vasavi Institute of Engineering \& Technology, Nandamuru, A.P.; India
}

Email address:

nayakeee@gmail.com (J. N. Bharothu), lalitha.kny@gmail.com (K Lalitha)

\section{To cite this article}

Jyothilal Nayak Bharothu, K Lalitha. Compensation of Voltage Flicker by Using Facts Devices. American Journal of Electrical Power and Energy Systems. Vol. 2, No. 3, 2013, pp. 66-80. doi: 10.11648/j.epes.20130203.12

\begin{abstract}
Voltage flicker occurs when heavy loads are periodically turned on and off in a weak distribution system. If the distribution system's short circuit capacity is not large enough, voltage fluctuations will occur. Voltage flickering can be extremely harmful to sensitive electronic equipment. Computerized equipment requires stable voltage to perform properly. This paper covers the contrasting approaches; dealing with the voltage flicker mitigation in three stages and assessing the related results in details. Initially, the voltage flicker mitigation, using FCTCR (Fixed Capacitor Thyristor Controlled Reactor), was simulated. Secondly, the compensation for the Static Synchronous Compensator (STATCOM) has been performed. In this case, injection of harmonics into the system caused some problems which were later overcome by using 12-pulse assignment of SATCOM and RLC filters. The obtained results show that STATCOM is very efficient and effective for the flicker compensation. All the simulations have been performed on the MATLAB Software.
\end{abstract}

Keywords: Voltage Flicker, STATCOM, FCTCR, Power Quality, RLC Filters Etc

\section{Introduction}

Voltage flicker occurs when heavy loads are periodically turned on and off in a weak distribution system. If the distribution system's short circuit capacity is not large enough, voltage fluctuations will occur. Starting large motors require an inrush of current, which causes a decrease in voltage. This voltage depression may cause a visible flicker on lighting circuits connected to the same power system. Voltage flickering can be extremely harmful to sensitive electronic equipment. Computerized equipment requires stable voltage to perform properly. For this reason, voltage flicker is a major power quality problem.

The magnitude of the voltage flicker depends upon the size and type of the electrical load that is producing the disturbance. A sag in voltage can also cause a voltage flicker; sudden voltage drops in the electrical distribution system can generate inrush current which can travel to sensitive equipment.

The relationship between power quality and distribution system has been a subject of interest for several years. The concept of power quality describes the quality of the supplier voltage in relation to the transient breaks, falling voltage, harmonics and voltage flicker. Voltage Flicker is the disturbance of lightning induced by voltage fluctuations. Very small variations are enough to induce lightning disturbance for human eye for a standard $230 \mathrm{~V}, 60 \mathrm{~W}$ coiled-coil filament lamp. The disturbance becomes perceptible for voltage variation frequency of $10 \mathrm{~Hz}$ and relative magnitude of $0.26 \%$. Huge non-linear industrial loads such as the electrical arc furnaces, pumps, welding machines, rolling mills and others are known as flicker generators. In this respect, the quality of supplied voltage is significantly reduced in an electrical power system and the oscillation of supplied voltage appears to be a major problem. Electric arc furnace, the main generator of voltage flicker, behaves in the form of a constant reactance and a variable resistance.

\subsection{Literature Survey}

D. Czarkowski et al [1] have analysed about the Voltage Flicker Mitigation Using

PWM-Based Distribution STATCOM in his paper "voltage flicker compensation using statcom"[1] .The author concluded thattheconcept of power quality describes the quality of the suppliervoltage in relation to the transient breaks, falling voltage, harmonics and voltage flicker

J. Mckim et al [2] have analysed about theUIE Flicker-meter Demystified in his paper "voltage flicker compensation using statcom"[2].The author concluded that the concept of The disturbance becomes perceptible for voltagevariation frequency of $10 \mathrm{~Hz}$ and relative magnitude 
of $0.26 \%$

R. Collantes-Bellido et al [3] have analysed about the Identification and Modeling of a

Three Phase Arc Furnace for Voltage Distribution Simulation in his paper "voltage flicker compensationusing statcom"[3]. The author concluded that the conceptof Huge non-linear industrial loads such as the electrical arc furnacespumps, welding machines, rolling mills andothers are known as flicker generators.

M. Zouiti et al [4] have analysed about the Electronic Based Equipment for Flicker Mitigation in his paper "voltage flicker compensation using statcom"[4]. The author concluded that the concept ofThe transformer-reactance system is modeled as alumped reactance, a furnace reactance (included connectioncables and busses) and a variable resistancewhich modelsthe arc.

S. Saadate et al al [5] have analysed about the Electronic Based Equipment for Flicker Mitigation in his paper "voltage flicker compensation using statcom"[5]. The author concluded that the concept ofTherefore, voltage flicker mitigation depends on reactivepower control

J. R. Clouston et al [5-14] have analysed about theField Demonstration of aDistribution Static Compensator Used to Mitigate Voltage Flicker in his paper "voltage flicker compensation using statcom"[5-14].In this type of compensation, the reactive power consumed by the compensator is keptconstant at a sufficient value.

M. W. Marshall et al [15-16] have analysed about the sing Series Capacitors to Mitigate VoltageFlicker Problems in his paper "voltage flicker compensation using statcom"[15-16].In this type, all the efforts aredone to decrease the voltage drop mentioned above, andfinally the reactive power is kept constant despite the loadfluctuations by controlling the line reactance.

J. Dolezal et al [17] have analysed about the Topologies and controlof active filters for flicker compensation International Symposiumon Industrial Electronics in his paper"voltage flicker compensation using statcom" [17]. In addition to the aforesaid procedures for thecompensators, the active filters are used for the voltageflickers mitigation as well

L. Gyugi,et al[18] have analysed about the Static Shunt Compensation for VoltageFlicker Reduction and Power Factor Correction in his paper "voltage flicker compensation using statcom"[18].Furthermore, the mitigatingdevices based on Static VAR Compensator (SVC) are the most frequentlyused devices for reduction in the voltage flicking.

Y. Hamachi et al [19] haveanalysed about the Voltage Fluctuation SuppressingSystem Using Thyristor Controlled Capacitors in his paper "voltage flicker compensation using statcom"[19].Furthermore, the mitigating devices based onThyristor Switched Capacitor TSC are the most frequentlyused devices for reduction in the voltage flicking.

F. FrankTYCAP, et al [20] have analysed about thePower Factor Correction EquipmentUsing Thyristor Controlled Capacitor for Arc Furnacesin his paper 'voltage flicker compensation using statcom"[20].Furthermore, the mitigating devices based onFCTCR are the most frequentlyused devices for reduction in the voltage flicking.

\subsection{Problem Formulation}

In this respect, the quality of supplied voltage is significantly reduced in an electrical power system and the oscillation of supplied voltage appears to be a major problem. Electric arc furnace, the main generator of voltage flicker, behaves in the form of a constant reactance and a variable resistance.

The transformer-reactance system is modeled as a lumped reactance, a furnace reactance (included connection cables and busses) and a variable resistancewhich models the arc. Connecting this type of load to the network produces voltage variation at the common point of supply to other consumers. The relative voltage drop is expressed by equation

$$
\frac{\Delta U}{U_{n}}=\frac{R \Delta P+X \Delta Q}{U_{n}^{2}}
$$

where $\Delta \mathrm{P}$ and $\Delta \mathrm{Q}$ are the variation in active and reactive power; Un is the nominal voltage and $\mathrm{R}$ and $\mathrm{X}$ are short circuit resistance and reactance. Since $\mathrm{R}$ is usually very small in comparison to $\mathrm{X}, \Delta \mathrm{U}$ is proportional to $\mathrm{Q}$ (reactive power). Therefore, voltage flicker mitigation depends on reactive power control. Two types of structures can be used for the compensation of the reactive power fluctuations that cause the voltage drop: A: shunt structure : in this type of compensation, the reactive power consumed by the compensator is kept constant at a sufficient value. B: series structure : in this type, all the efforts are done to decrease the voltage drop mentioned above, and finally the reactive power is kept constant despite the load fluctuations by controlling the line reactance.

In addition to the aforesaid procedures for the compensators, the active filters are used for the voltage flickers mitigation as well . Furthermore, the mitigating devices based on Static VAR Compensator (SVC) such as Thyristor Switched Capacitor TSC , Thyristor Controlled Reactor (TCR), and FCTCR, are the most frequently used devices for reduction in the voltage flicking. SVC devices achieved an acceptable level ofmitigation, but because of their complicated control algorithms, they have problems such as injecting a large amount of current harmonics to the system and causing spikes in voltage waveforms. Advent of FACTS devices make them ideal for use in a power system and especially in the voltage flicker mitigation. In this respect, the FACTS devices based on voltage-source converters have been able to improve the problems related to SVC. A new technique based on a novel control algorithm, which extracts the voltage disturbance to suppress the voltage flicker, is presented in this paper. The technique is to use STATCOM for voltage flicker compensation to overcome the aforementioned problems related to other techniques. 


\section{Introductions to Power Quality}

The power quality problem is defined as any problem manifested in voltage, current or frequency deviations that result in mal-operation of customer equipment. The power quality problem causes the deterioration of performance of various sensitive electronic and electric equipments. The good quality of power can be specified as The supply voltage should be within guaranteed tolerance of declared value. The wave shape should be pure sine wave within allowable limits for distortion. The voltage should be balanced in all three phases. Supply should be reliable i.e. continuous availability without interruption Modern industrial machinery and commercial computer networks are prone to many different failure modes. When the assembly line stops, or the computer network crashes for no apparent reason, very often the electric power quality is suspected. It is a convenient culprit, as it is invisible and not easy to defend. Power quality problems may be very difficult to troubleshoot, and often the electric power may not have any relation to the actual problem. For example, in an industrial plant the faults of an automated assembly machine may ultimately be traced to fluctuations in the compressed air supply or a faulty hydraulic valve. Or in an office building, the problems on a local area network may be find their root cause with coaxial cable tee locations that are too close together, causing reflections and signal loss.

The contemporary container crane industry, like many other industry segments, is often enamoured by the bells and whistles, colourful diagnostic displays, high speed performance, and levels of automation that can be achieved Although these features and their indirectly related computer based enhancements are key issues to an efficient terminal operation, we must not forget the foundation upon which we are building. Power quality is the mortar which bonds the Foundation blocks. Power quality also affects terminal operating economics, crane reliability, our environment, and initial investment in power distribution systems to support new crane installations.

To quote the utility company newsletter which accompanied the last monthly issue of my home utility billing: 'Using electricity wisely is a good environmental and business practice which saves you money, reduces emissions from generating plants, and conserves our Natural resources.' As we are all aware, container crane performance requirements continue to increase at an astounding rate. Next generation container cranes, already in the bidding process, will require average power demands of 1500 to $2000 \mathrm{~kW}$ - almost double the total average Demand three years ago. The rapid increase in power demand levels, an increase in container crane population, SCR converter crane drive retrofits and the large AC and DC drives needed to power and control these cranes will increase awareness of the power quality issue in the very near future.

\subsection{Power Quality Problems}

For the purpose of this article, we shall define power quality problems as:

'Any power problem that results in failure or disoperation of customer equipment manifests itself as an economic burden to the user, or produces negative impacts on the environment.'

When applied to the container crane industry, the power issues which degrade power quality include:

- Power Factor

- Harmonic Distortion

- Voltage Transients

- Voltage Sags or Dips

- Voltage Swells

The AC and DC variable speed drives utilized on board container cranes are significant contributors to total harmonic current and voltage distortion. Whereas SCR phase control creates the desirable average power factor, DC SCR drives operate at less than this. In addition, line notching occurs when SCR's commutate, creating transient peak recovery voltages that can be 3 to 4 times the nominal line voltage depending upon the system impedance and the size of the drives. The frequency and severity of these power system disturbances varies with the speed of the drive. Harmonic current injection by AC and DC drives will be highest when the drives are operating at slow speeds. Power factor will be lowest when DC drives are operating at slow speeds or during initial acceleration and deceleration periods, increasing to its maximum value when the SCR's are fazed on to produce rated or base speed.

Above base speed, the power factor essentially remains constant. Unfortunately, container cranes can spend considerable time at low speeds as the operator attempts to spot and land containers. Poor power factor places a greater $\mathrm{kVA}$ demand burden on the utility or engine-alternator power source. Low power factor loads can also affect the voltage stability which can ultimately result in detrimental effects on the life of sensitive electronic equipment or even intermittent malfunction. Voltage transients created by DC drive SCR line notching, AC drive voltage chopping, and high frequency harmonic voltages and currents are all significant sources of noise and disturbance to sensitive electronic equipment

It has been our experience that end users often do not associate power quality problems with Container cranes, either because they are totally unaware of such issues or there was no economic Consequence if power quality was not addressed. Before the advent of solid-state power supplies, Power factor was reasonable, and harmonic current injection was minimal. Not until the crane Population multiplied, power demands per crane increased, and static power conversion became the way of life, did power quality issues begin to emerge.

Even as harmonic distortion and power Factor issues surfaced, no one was really prepared. Even today, crane builders and electrical drive System vendors avoid the issue 
during competitive bidding for new cranes. Rather than focus on Awareness and understanding of the potential issues, the power quality issue is intentionally or Unintentionally ignored. Power quality problem solutions are available. Although the solutions are not free, in most cases, they do represent a good return on investment. However, if power quality is not specified, it most likely will not be delivered.

Power quality can be improved through:

- Power factor correction,

- Harmonic filtering,

- Special line notch filtering,

- Transient voltage surge suppression,

- Proper earthing systems.

In most cases, the person specifying and/or buying a container crane may not be fully aware of the potential power quality issues. If this article accomplishes nothing else, we would hope to provide that awareness.

In many cases, those involved with specification and procurement of container cranes may not be cognizant of such issues, do not pay the utility billings, or consider it someone else's concern. As a result, container crane specifications may not include definitive power quality criteria such as power factor correction and/or harmonic filtering. Also, many of those specifications which do require power quality equipment do not properly define the criteria. Early in the process of preparing the crane specification:

- Consult with the utility company to determine regulatory or contract requirements that must be

satisfied, if any.

- Consult with the electrical drive suppliers and determine the power quality profiles that can be expected based on the drive sizes and technologies proposed for the specific project.

- Evaluate the economics of power quality correction not only on the present situation, but consider the impact of future utility deregulation and the future development plans for the terminal

\subsection{The Benefits of Power Quality}

Power quality in the container terminal environment impacts the economics of the terminal operation, affects reliability of the terminal equipment, and affects other consumers served by the same utility service. Each of these concerns is explored in the following paragraphs.

\subsubsection{Economic Impact}

The economic impact of power quality is the foremost incentive to container terminal operators. Economic impact can be significant and manifest itself in several ways:

\subsubsection{Power Factor Penalties}

Many utility companies invoke penalties for low power factor on monthly billings. There is no industry standard followed by utility companies. Methods of metering and calculating power factor penalties vary from one utility company to the next. Some utility companies actually meter kVAR usage and establish a fixed rate times the number of kVAR-hours consumed. Other utility companies monitor kVAR demands and calculate power factor. If the power factor falls below a fixed limit value over a demand period, a penalty is billed in the form of an adjustment to the peak demand charges. A number of utility companies servicing container terminal equipment do not yet invoke power factor penalties. However, their service contract with the Port may still require that a minimum power factor over a defined demand period be met. The utility company may not continuously monitor power factor or kVAR usage and reflect them in the monthly utility billings; however, they do reserve the right to monitor the Port service at any time. If the power factor criteria set forth in the service contract are not met, the user may be penalized, or required to take corrective actions at the user's expense. One utility company, which supplies power service to several east coast container terminals in the USA, does not reflect power factor penalties in their monthly billings, however, their service contract with the terminal reads as follows:

'The average power factor under operating conditions of customer's load at the point where service is metered shall be not less than $85 \%$. If below $85 \%$, the customer may be required to furnish, install and maintain at its expense corrective apparatus which will increase the Power factor of the entire installation to not less than $85 \%$. The customer shall ensure that no excessive harmonics or transients are introduced on to the [utility] system. This may require special power conditioning equipment or filters. The IEEE Std. 519-1992 is used as a guide in Determining appropriate design requirements.'

The Port or terminal operations personnel, who are responsible for maintaining container cranes, or specifying new container crane equipment, should be aware of these requirements. Utility deregulation will most likely force utilities to enforce requirements such as the example above. Terminal operators who do not deal with penalty issues today may be faced with some rather severe penalties in the future. A sound, future terminal growth plan should include contingencies for addressing the possible economic impact of utility deregulation.

\subsubsection{System Losses}

Harmonic currents and low power factor created by nonlinear loads, not only result in possible power factor penalties, but also increase the power losses in the distribution system. These losses are not visible as a separate item on your monthly utility billing, but you pay for them each month. Container cranes are significant contributors to harmonic currents and low power factor. Based on the typical demands of today's high speed container cranes, correction of power factor alone on a typical state of the art quay crane can result in a reduction of system losses that converts to a 6 to $10 \%$ reduction in the monthly utility billing. For most of the larger terminals, this is a significant annual saving in the cost of operation. 


\subsubsection{Power Service Initial Capital Investments}

The power distribution system design and installation for new terminals, as well as modification of systems for terminal capacity upgrades, involves high cost, specialized, high and medium voltage equipment. Transformers, switchgear, feeder cables, cable reel trailing cables, collector bars, etc. must be sized based on the kVA demand. Thus cost of the equipment is directly related to the total kVA demand. As the relationship above indicates, kVA demand is inversely proportional to the overall power factor, i.e. a lower power factor demands higher $\mathrm{kVA}$ for the same $\mathrm{kW}$ load. Container cranes are one of the most significant users of power in the terminal. Since container cranes with DC, 6 pulse, SCR drives operate at relatively low power factor, the total kVA demand is significantly larger than would be the case if power factor correction equipment were supplied on board each crane or at some common bus location in the terminal. In the absence of power quality corrective equipment, transformers are larger, switchgear current ratings must be higher, feeder cable copper sizes are larger, collector system and cable reel cables must be larger, etc. Consequently, the cost of the initial power distribution system equipment for a system which does not address power quality will most likely be higher than the same system which includes power quality equipment.

\subsubsection{Equipment Reliability}

Poor power quality can affect machine or equipment reliability and reduce the life ofcomponents. Harmonics, voltage transients, and voltage system sags and swells are all power quality problems and are all interdependent. Harmonics affect power factor, voltage transientscan induce harmonics, the same phenomena which create harmonic current injection in DC SCR variable speed drives are responsible for poor power factor, and dynamically varying power factor of the same drives can create voltage sags and swells. The effects of harmonic distortion, harmonic currents, and line notch ringing can be mitigated using specially designed filters.

\subsubsection{Power System Adequacy}

When considering the installation of additional cranes to an existing power distribution system, a power system analysis should be completed to determine the adequacy of the system to support additional crane loads. Power quality corrective actions may be dictated due to inadequacy of existing power distribution systems to which new or relocated cranes are to be connected. In other words, addition of power quality equipment may render a workable scenario on an existing power distribution system, which would otherwise be inadequate to support additional cranes without high risk of problems.

\subsubsection{Environment}

No issue might be as important as the effect of power quality on our environment. Reduction in system losses and lower demands equate to a reduction in the consumption of our natural $\mathrm{nm}$ resources and reduction in power plant emissions. It is our responsibility as occupants of this planet to encourage conservation of our natural resources and support measures which improve our air quality

\section{Introductions to Facts}

Flexible AC Transmission Systems, called FACTS, got in the recent years a well-known term for higher controllability in power systems by means of power electronic devices. Several FACTS-devices have been introduced for various applications worldwide. A number of new types of devices are in the stage of being introduced in practice.

In most of the applications the controllability is used to avoid cost intensive or landscape requiring extensions of power systems, for instance like upgrades or additions of substations and power lines. FACTS-devices provide a better adaptation to varying operational conditions and improve the usage of existing installations. The basic applications of FACTS-devices are:

- Power flow control,

- Increase of transmission capability,

- Voltage control,

- Reactive power compensation,

- Stability improvement,

- Power quality improvement,

- Power conditioning,

- Flicker mitigation,

- Interconnection of renewable and distributed generation and storages.

The usage of lines for active power transmission should be ideally up to the thermal limits. Voltage and stability limits shall be shifted with the means of the several different FACTS devices. It can be seen that with growing line length, the opportunity for FACTS devices gets more and more important.

The influence of FACTS-devices is achieved through switched or controlled shunt compensation, series compensation or phase shift control. The devices work electrically as fast current, voltage or impedance controllers. The power electronic allows very short reaction times down to far below one second.

The development of FACTS-devices has started with the growing capabilities of power electronic components. Devices for high power levels have been made available in converters for high and even highest voltage levels. The overall starting points are network elements influencing the reactive power or the impedance of a part of the power system. Figure 3.2 shows a number of basic devices separated into the conventional ones and the FACTS-devices.

For the FACTS side the taxonomy in terms of 'dynamic' and 'static' needs some explanation. The term 'dynamic' is used to express the fast controllability of FACTS-devices provided by the power electronics. This is one of the main differentiation factors from the conventional devices. The 
term 'static' means that the devices have no moving parts like mechanical switches to perform the dynamic controllability. Therefore most of the FACTS-devices can equally be static and dynamic.

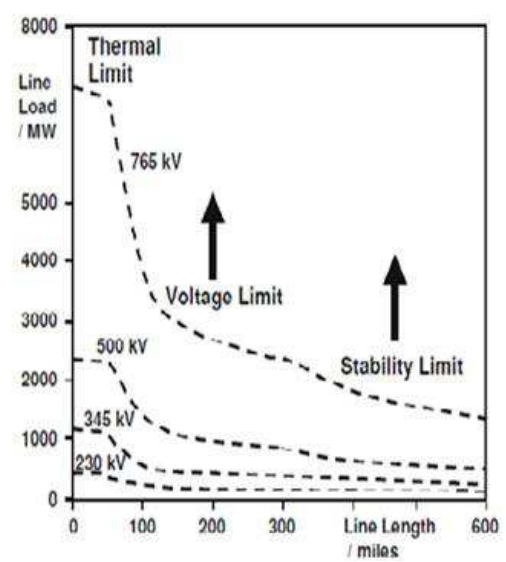

Fig 3.1. Operational limits of transmission lines for different voltage levels

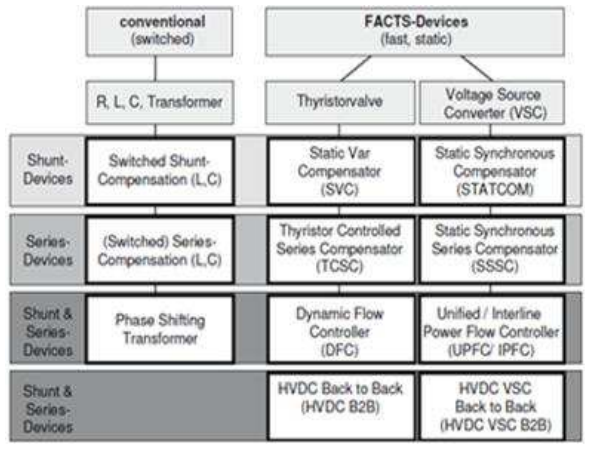

Fig 3.2. Overview of FACTS devices

The left column in Figure 3.2 contains the conventional devices build out of fixed or mechanically switch able components like resistance, inductance or capacitance together with transformers. The FACTS-devices contain these elements as well but use additional power electronic valves or converters to switch the elements in smaller steps or with switching patterns within a cycle of the alternating current. The left column of FACTS-devices uses Thyristor valves or converters. These valves or converters are well known since several years. They have low losses because of their low switching frequency of once a cycle in the converters or the usage of the Thyristors to simply bridge impedances in the valves.

The right column of FACTS-devices contains more advanced technology of voltage source converters based today mainly on Insulated Gate Bipolar Transistors (IGBT) or Insulated Gate Commutated Thyristors (IGCT). Voltage Source Converters provide a free controllable voltage in magnitude and phase due to a pulse width modulation of the IGBTs or IGCTs. High modulation frequencies allow to get low harmonics in the output signal and even to compensate disturbances coming from the network. The disadvantage is that with an increasing switching frequency, the losses are increasing as well. Therefore special designs of the converters are required to compensate this.

\subsection{Shunt Devices}

The most used FACTS-device is the SVC or the version with Voltage Source Converter called STATCOM. These shunt devices are operating as reactive power compensators. The main applications in transmission, distribution and industrial networks are:

- Reduction of unwanted reactive power flows and therefore reduced network losses.

- Keeping of contractual power exchanges with balanced reactive power.

- Compensation of consumers and improvement of power quality especially with huge demand fluctuations like industrial machines, metal melting plants, railway or underground train systems.

- Compensation of Thyristor converters e.g. in conventional HVDC lines.

- Improvement of static or transient stability.

Almost half of the SVC and more than half of the STATCOMs are used for industrial applications. Industry as well as commercial and domestic groups of users require power quality. Flickering lamps are no longer accepted, nor are interruptions of industrial processes due to insufficient power quality. Railway or underground systems with huge load variations require SVCs or STATCOMs.

\subsubsection{SVC}

Electrical loads both generate and absorb reactive power. Since the transmitted load varies considerably from one hour to another, the reactive power balance in a grid varies as well. The result can be unacceptable voltage amplitude variations or even a voltage depression, at the extreme a voltage collapse.

A rapidly operating Static Var Compensator (SVC) can continuously provide the reactive power required to control dynamic voltage oscillations under various system conditions and thereby improve the power system transmission and distribution stability.

Applications of the SVC systems in transmission systems:

a. To increase active power transfer capacity and transient stability margin

b. To damp power oscillations

c. To achieve effective voltage control

In addition, SVCs are also used

\subsubsection{In Transmission System}

a. To reduce temporary over voltages

b. To damp sub synchronous resonances

c. To damp power oscillations in interconnected power systems

\subsubsection{In Traction Systems}
a. To balance loads
b. To improve power factor 
c. To improve voltage regulation

\subsubsection{In HVDC Systems}

a. To provide reactive power to ac-dc converters

\subsubsection{In Arc Furnaces}

a. To reduce voltage variations and associated light flicker

Installing an SVC at one or more suitable points in the network can increase transfer capability and reduce losses while maintaining a smooth voltage profile under different network conditions. In addition an SVC can mitigate active power oscillations through voltage amplitude modulation.

SVC installations consist of a number of building blocks. The most important is the Thyristor valve, i.e. stack assemblies of series connected anti-parallel Thyristors to provide controllability. Air core reactors and high voltage AC capacitors are the reactive power elements used together with the Thyristor valves. The step up connection of this equipment to the transmission voltage is achieved through a power transformer.

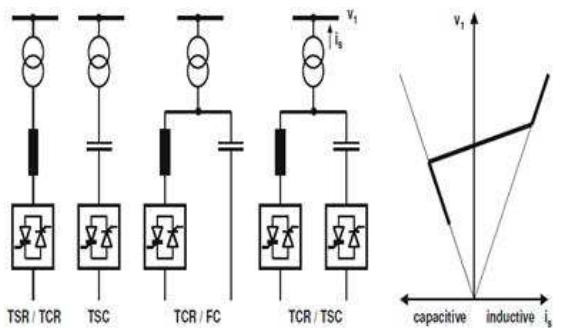

Fig 3.3. SVC building blocks and voltage / current characteristic

In principle the SVC consists of Thyristor Switched Capacitors (TSC) and Thyristor Switched or Controlled Reactors (TSR / TCR). The coordinated control of a combination of these branches varies the reactive power as shown in Figure. The first commercial SVC was installed in 1972 for an electric arc furnace. On transmission level the first SVC was used in 1979. Since then it is widely used and the most accepted FACTS-device.

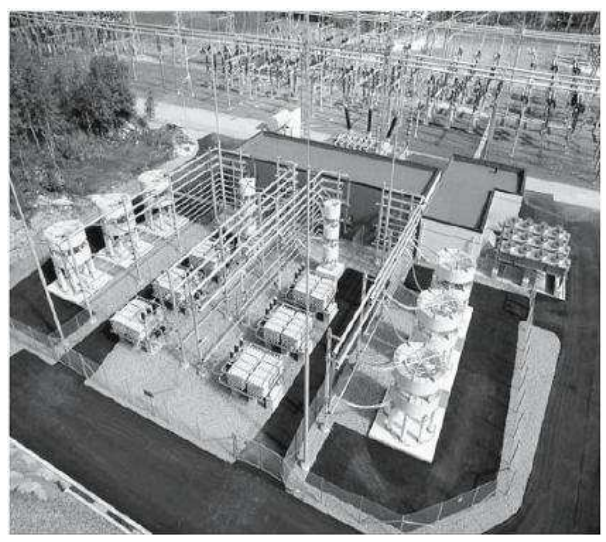

Fig 3.4. SVC using a TCR and an FC

In this arrangement, two or more FC (fixed capacitor) banks are connected to a TCR (thyristor controlled reactor) through a step-down transformer. The rating of the reactor is chosen larger than the rating of the capacitor by an amount to provide the maximum lagging vars that have to be absorbed from the system. By changing the firing angle of the thyristor controlling the reactor from $90^{\circ}$ to $180^{\circ}$, the reactive power can be varied over the entire range from maximum lagging vars to leading vars that can be absorbed from the system by this compensator.

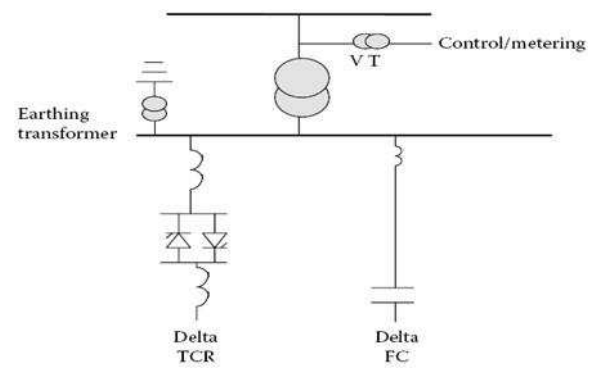

Fig 3.5. SVC using a TCR and an FC

\subsubsection{SVC of the FC/TCR Type}

The main disadvantage of this configuration is the significant harmonics that will be generated because of the partial conduction of the large reactor under normal sinusoidal steady-state operating condition when the SVC is absorbing zero MVAr. These harmonics are filtered in the following manner. Triplex harmonics are canceled by arranging the TCR and the secondary windings of the step-down transformer in delta connection. The capacitor banks with the help of series reactors are tuned to filter fifth, seventh, and other higher-order harmonics as a high-pass filter. Further losses are high due to the circulating current between the reactor and capacitor banks.

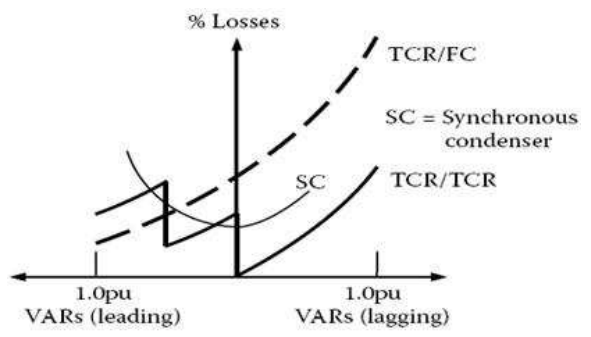

Fig 3.6. Comparison of the loss characteristics of TSC-TCR, TCFC

\section{Compensators and synchronous condenser}

These SVCs do not have a short-time overload capability because the reactors are usually of the air-core type. In applications requiring overload capability, TCR must be designed for short-time overloading, or separate thyristor-switched overload reactors must be employed.

\subsubsection{Sve Using a TCR and TSC}

This compensator overcomes two major shortcomings of the earlier compensators by reducing losses under operating conditions and better performance under large system disturbances. In view of the smaller rating of each capacitor bank, the rating of the reactor bank will be $1 / \mathrm{n}$ times the maximum output of the SVC, thus reducing the harmonics 
generated by the reactor. In those situations where harmonics have to be reduced further, a small amount of FCs tuned as filters may be connected in parallel with the TCR.

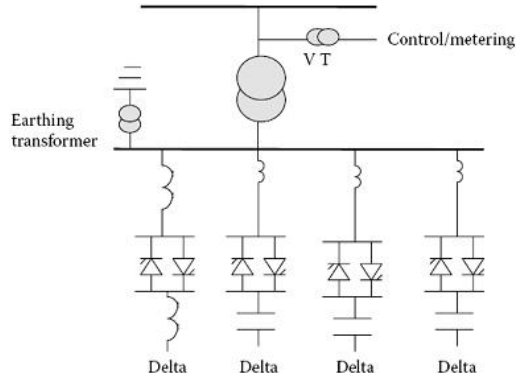

Fig 3.7. SVC of combined TSC and TCR type

When large disturbances occur in a power system due to load rejection, there is a possibility for large voltage transients because of oscillatory interaction between system and the SVC capacitor bank or the parallel. The LC circuit of the SVC in the FC compensator. In the TSC-TCR scheme, due to the flexibility of rapid switching of capacitor banks without appreciable disturbance to the power system, oscillations can be avoided, and hence the transients in the system can also be avoided. The capital cost of this SVC is higher than that of the earlier one due to the increased number of capacitor switches and increased control complexity.

\subsubsection{Statcom}

In 1999 the first SVC with Voltage Source Converter called STATCOM (STATic COMpensator) went into operation. The STATCOM has a characteristic similar to the synchronous condenser, but as an electronic device it has no inertia and is superior to the synchronous condenser in several ways, such as better dynamics, a lower investment cost and lower operating and maintenance costs. A STATCOM is build with Thyristors with turn-off capability like GTO or today IGCT or with more and more IGBTs. The static line between the current limitations has a certain steepness determining the control characteristic for the voltage.

The advantage of a STATCOM is that the reactive power provision is independent from the actual voltage on the connection point. This can be seen in the diagram for the maximum currents being independent of the voltage in comparison to the SVC. This means, that even during most severe contingencies, the STATCOM keeps its full capability.

In the distributed energy sector the usage of Voltage Source Converters for grid interconnection is common practice today. The next step in STATCOM development is the combination with energy storages on the DC-side. The performance for power quality and balanced network operation can be improved much more with the combination of active and reactive power.

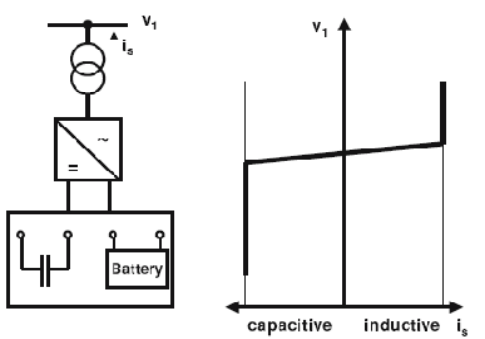

Fig 3.8. STATCOM structure and voltage / current characteristic

STATCOMs are based on Voltage Sourced Converter (VSC) topology and utilize either Gate-Turn-off Thyristors (GTO) or Isolated Gate Bipolar Transistors (IGBT) devices The STATCOM is a very fast acting, electronic equivalent of a synchronous condenser. If the STATCOM voltage, Vs, (which is proportional to the dc bus voltage $\mathrm{Vc}$ ) is larger than bus voltage, Es, then leading or capacitive VARS are produced. If Vs is smaller thenEs then lagging or inductive VARS are produced.

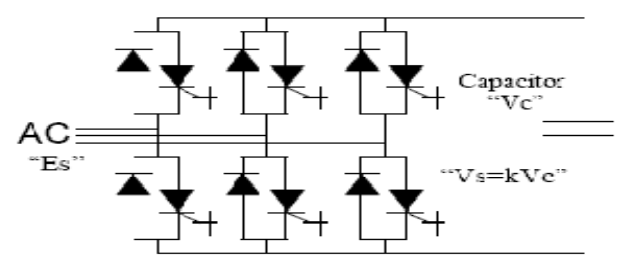

Fig 3.8 6. Pulses STATCOM

The three phases STATCOM makes use of the fact that on a three phase, fundamental frequency, steady state basis, and the instantaneous power entering a purely reactive device must be zero. The reactive power in each phase is supplied by circulating the instantaneous real power between the phases. This is achieved by firing the GTO/diode switches in a manner that maintains the phase difference between the ac bus voltage ES and the STATCOM generated voltage VS. Ideally it is possible to construct a device based on circulating instantaneous power which has no energy storage device (ie no dc capacitor).

A practical STATCOM requires some amount of energy storage to accommodate harmonic power and ac system unbalances, when the instantaneous real power is non-zero. The maximum energy storage required for the STATCOM is much less than for a TCR/TSC type of SVC compensator of comparable rating.

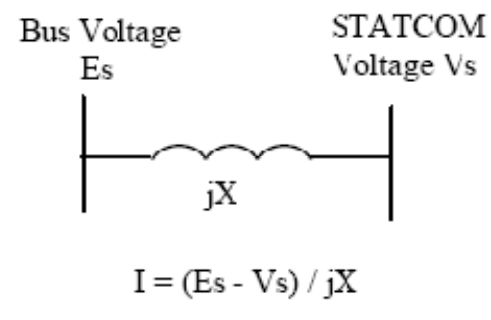

Fig 3.9. STATCOM Equivalent Circuit

Several different control techniques can be used for the 
firing control of the STATCOM. Fund.amental switching of the GTO/diode once per cycle can be used. This approach will minimize switching losses, but will generally utilize more complex transformer topologies. As an alternative, Pulse Width Modulated (PWM) techniques, which turn on and off the GTO or IGBT switch more than once per cycle, can be used. This approach allows for simpler transformer topologies at the expense of higher switching losses.

The 6 PulseSTATCOM using 1 harmonics. There are a fundamental switching will of course produce the $6 \mathrm{~N}$ variety of methods to decrease the harmonics. These methods include the basic 12 pulse configuration with parallel star / delta transformer connections, a complete elimination of 5th and 7th harmonic current using series connection of star/star and star/delta transformers and a quasi 12 pulse method with a single star-star transformer, and two secondary windings, using control of firing phase shift between the two 6 pulse bridges. This angle to produce a 30 method can be extended to produce a 24 pulse and a 48 pulse STATCOM, thus eliminating harmonics even further. Another possible approach for harmonic cancellation is a multi-level configuration which allows for more than one switching element per level and therefore more than one switching in each bridge arm. The ac voltage derived has a staircase effect, dependent on the number of levels. This staircase voltage can be controlled to eliminate harmonics.

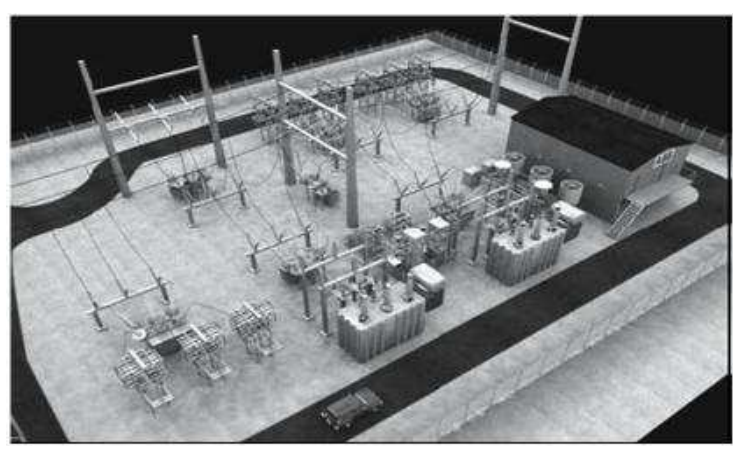

Fig 3.10. Substation with a STATCOM

\subsection{Series Devices}

Series devices have been further developed from fixed or mechanically switched compensations to the Thyristor Controlled Series Compensation (TCSC) or even Voltage Source Converter based devices.

The main applications are:

- Reduction of series voltage decline in magnitude and angle over apower line,

- Reduction of voltage fluctuations within defined limits during changing power transmissions,

- Improvement of system damping resp. damping of oscillations,

- Limitation of short circuit currents in networks or substations,

- Avoidance of loop flows resp. power flow adjustments.

\subsubsection{Tcsc}

Thyristor Controlled Series Capacitors (TCSC) address specific dynamical problems in transmission systems. Firstly it increases damping when large electrical systems are interconnected. Secondly it can overcome the problem of Sub Synchronous Resonance (SSR), a phenomenon that involves an interaction between large thermal generating units and series compensated transmission systems.

The TCSC's high speed switching capability provides a mechanism for controlling line power flow, which permits increased loading of existing transmission lines, and allows for rapid readjustment of line power flow in response to various contingencies. The TCSC also can regulate steady-state power flow within its rating limits.

From a principal technology point of view, the TCSC resembles the conventional series capacitor. All the power equipment is located on an isolated steel platform, including the Thyristor valve that is used to control the behavior of the main capacitor bank. Likewise the control and protection is located on ground potential together with other auxiliary systems. Figure shows the principle setup of a TCSC and its operational diagram. The firing angle and the thermal limits of the Thyristors determine the boundaries of the operational diagram.

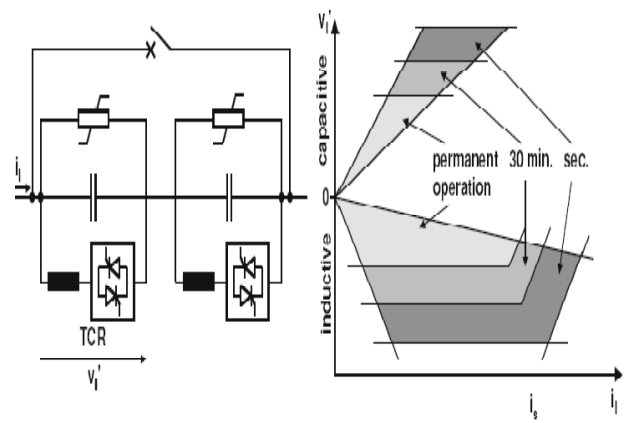

Fig 3.11. principle setup of a TCSC and its operational diagram

Advantages

- Continuous control of desired compensation level

- Direct smooth control of power flow within the network

- Improved capacitor bank protection

- Local mitigation of sub synchronous resonance (SSR). This permits higher levels of compensation in networks where interactions with turbine-generator torsional vibrations or with other control or measuring systems are of concern.

- Damping of electromechanical $(0.5-2 \mathrm{~Hz})$ power oscillations which often arise between areas in a large interconnected power network. These oscillations are due to the dynamics of inter area power transfer and often exhibit poor damping when the aggregate power tranfer over a corridor is high relative to the transmission strength.

\subsection{Shunt and Series Devices}

\section{Dynamic Power Flow Controller}

A new device in the area of power flow control is the 
Dynamic Power Flow Controller (DFC). The DFC is a hybrid device between a Phase Shifting Transformer (PST) and switched series compensation.

A functional single line diagram of the Dynamic Flow Controller is shown in Figure 1.19. The Dynamic Flow Controller consists of the following components:

- a standard phase shifting transformer with tap-changer (PST)

- series-connected Thyristor Switched Capacitors and Reactors

(TSC / TSR)

- A mechanically switched shunt capacitor (MSC). (This is optional depending on the system reactive power requirements)

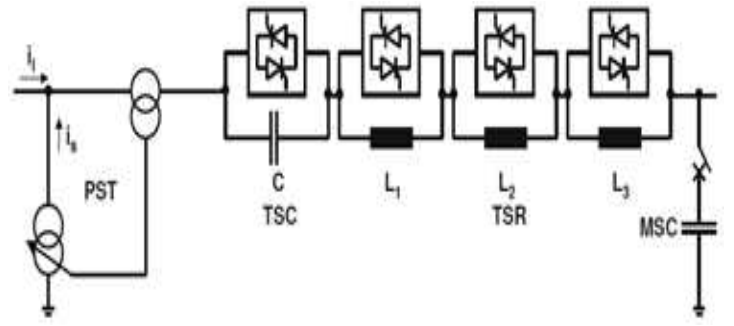

Fig 3.12. Principle configuration of DFC

Based on the system requirements, a DFC might consist of a number of series TSC or TSR. The mechanically switched shunt capacitor (MSC) will provide voltage support in case of overload and other conditions. Normally the reactance of reactors and the capacitors are selected based on a binary basis to result in a desired stepped reactance variation. If a higher power flow resolution is needed, a reactance equivalent to the half of the smallest one can be added.

The switching of series reactors occurs at zero current to avoid any harmonics. However, in general, the principle of phase-angle control used in TCSC can be applied for a continuous control as well. The operation of a DFC is based on the following rules:

- TSC / TSR are switched when a fast response is required.

- The relieve of overload and work in stressed situations is handled by the TSC / TSR.

- The switching of the PST tap-changer should be minimized particularly for the currents higher than normal loading.

- The total reactive power consumption of the device can be optimized by the operation of the MSC, tap changer and the switched capacities and reactors.

In order to visualize the steady state operating range of the DFC, we assume an inductance in parallel representing parallel transmission paths. The overall control objective in steady state would be to control the distribution of power flow between the branch with the DFC and the parallel path. This control is accomplished by control of the injected series voltage.

The PST (assuming a quadrature booster) will inject a voltage in quadrature with the node voltage. The controllable reactance will inject a voltage in quadrature with the throughput current. Assuming that the power flow has a load factor close to one, the two parts of the series voltage will be close to collinear. However, in terms of speed of control, influence on reactive power balance and effectiveness at high/low loading the two parts of the series voltage has quite different characteristics. The steady state control range for loadings up to rated current is illustrated in Figure 3.5.2, where the $\mathrm{x}$-axis corresponds to the throughput current and the $y$-axis corresponds to the injected series voltage.

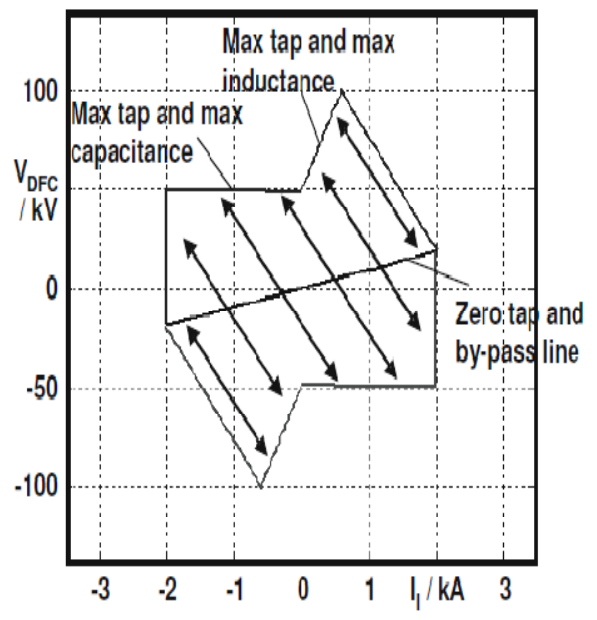

Fig3.13 Operational diagram of a DFC

Operation in the first and third quadrants corresponds to reduction of power through the DFC, whereas operation in the second and fourth quadrants corresponds to increasing the power flow through the DFC. The slope of the line passing through the origin (at which the tap is at zero and TSC / TSR are bypassed) depends on the short circuit reactance of the PST.

Starting at rated current $(2 \mathrm{kA})$ the short circuit reactance by itself provides an injected voltage (approximately $20 \mathrm{kV}$ in this case). If more inductance is switched in and/or the tap is increased, the series voltage increases and the current through the DFC decreases (and the flow on parallel branches increases). The operating point moves along lines parallel to the arrows in the figure. The slope of these arrows depends on the size of the parallel reactance. The maximum series voltage in the first quadrant is obtained when all inductive steps are switched in and the tap is at its maximum.

Now, assuming maximum tap and inductance, if the throughput current decreases (due e.g. to changing loading of the system) the series voltage will decrease. At zero current, it will not matter whether the TSC / TSR steps are in or out, they will not contribute to the series voltage. Consequently, the series voltage at zero current corresponds to rated PST series voltage. Next, moving into the second quadrant, the operating range will be limited by the line corresponding to maximum tap and the capacitive 
step being switched in (and the inductive steps by-passed). In this case, the capacitive step is approximately as large as the short circuit reactance of the PST, giving an almost constant maximum voltage in the second quadrant.

\section{Voltage Flicker}

Flicker is a difficult problem to quantify and to solve. The untimely combination of the following factors is required for flicker to be a problem: 1) some deviation in voltage supplying lighting circuits and 2) a person being present to view the possible change in light intensity due to the voltage deviation. The human factor significantly complicates the issue and for this reason flicker has historically been deemed "a problem of perception." The voltage deviations involved are often much less than the thresholds of susceptibility for electrical equipment, so major operating problems are only experienced in rare cases. To office personnel, on the other hand, voltage deviations on the order of a few tenths of one percent could produce extremely annoying fluctuations in the output of lights, especially if the frequency of repetitive deviations is 5-15 Hz. Due to the clear relationship between voltage deviation and light response, the term "flicker" often means different things to different people with the interpretation primarily governed by the concerns of a particular discussion.

\section{Flicker Measurement Introduction}

The power supply network voltage varies over time due to perturbations that occur in the processes of electricity generation, transmission and distribution. Interaction of electrical loads with the network causes further deterioration of the electrical power quality. High power loads that draw fluctuating current, such as large motor drives and arc furnaces, cause low frequency cyclic voltage variations that result in: flickering of light sources which can cause significant physiological discomfort, physical and psychological tiredness, and even pathological effects for human beings, problems with the stability of electrical devices and electronic circuits.

\subsection{Controlling System}

The concept of instantaneous reactive power is used for the controlling system. Following this, the 3-phase voltage upon the use of the park presented by Akagi [24] has been transformed to the synchronous reference frame (Park or dq0 transformation). This transformation leads to the appearances of three instantaneous space vectors: $\mathrm{Vd}$ on the $\mathrm{d}$-axis (real or direct axis), Vq on the q-axis (imaginary or quadrature axis) and V0, from the 3-phase voltage of Va, $\mathrm{Vb}$ and $\mathrm{Vc}$. The related equations of this transformation, expressed in the MATLAB software, are as follows:

$$
\begin{aligned}
& V_{d}=\frac{2}{3}\left(V_{a} \sin (\omega t)+V_{b} \sin \left(\omega t-\frac{2 \pi}{3}\right)+V_{C} \sin \left(\omega t+\frac{2 \pi}{3}\right)\right) \\
& V_{q}=\frac{2}{3}\left(V_{a} \cos (\omega t)+\cos \left(\omega t-\frac{2 \pi}{3}\right)+\cos \left(\omega t+\frac{2 \pi}{3}\right)\right) \\
& V_{0}=\frac{1}{3}\left(V_{a}+V_{b}+V_{c}\right)
\end{aligned}
$$

A dynamic computation shows that the voltage oscillations in the connecting node of the flicker-generating load to the network are created by 3 vectors: real current (ip), imaginary current (iq) and the derivative of the real current with respectto time $\left(\left(^{d i_{p}} \begin{array}{c}d t \\ d t\end{array}\right)\right.$. In general, for the complete voltage flicker compensation, the compensating current (ic) regarding the currents converted to the $\mathrm{dq} 0$ axis is given as

$$
i_{c}=j\left(i_{q}+i_{p} \frac{R}{X} f+\frac{1}{\omega} \frac{d i_{p}}{d \omega} f+k\right)
$$

where $\mathrm{R}$ and $\mathrm{X}$ are the synchronous resistance and reactance of the line and $f$ is the correcting coefficient. The constant $k$ is also used to eliminate the average reactive power of the network. If the compensation current of the above equation is injected to the network, the whole voltage flicker existing in the network will be eliminated. Regarding the equation, related to the dq-transformation of the 3-phase-voltages to the instantaneous vectors, it is obvious that under the conditions of accessing an average voltage flicker, $\mathrm{Vd}$ and $\mathrm{V0}$, the obtained values are close to zero and $\mathrm{Vq}$ is a proper value adapting to the voltage oscillation of the network. This state of the 3-phase voltage flicker is presented in the following figures (simulated in the MATLAB Simulink package):

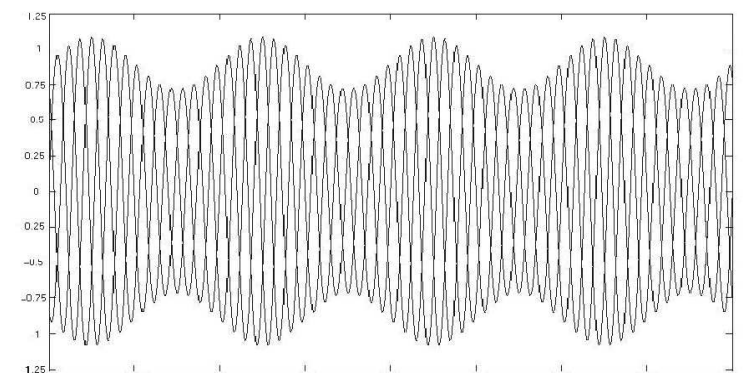

Fig 4.1. voltage flicker extended to circuit

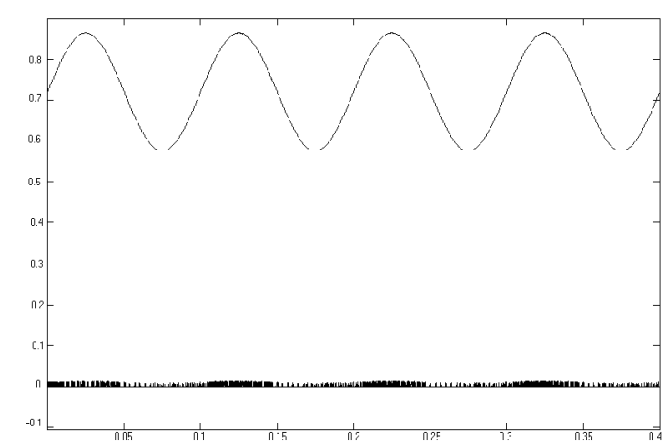

Fig 4.2. instantaneous components of the 3-phase voltage flicker waveform 
Then, we may conclude that the decrease of the voltage flicker of the network and the compensating control to decrease the voltage flicker can be limited only based on the amount of the imaginary component of the instantaneous voltage $(\mathrm{Vq})$.

\subsection{Compensation System}

A typical two-bus power system shown in figure 5.3 is simulated in MATLAB for this study. It can be seen that the voltage oscillation was produced by a 3-phase flicker source connected to the main bus-bar. The complete STATCOM control system scheme implemented on MATLAB is shown in figure 5.3. First, using a 3-phase converter to dq0, the instantaneous vectors $\mathrm{Vd}, \mathrm{Vq}$ and $\mathrm{V} 0$, are evaluated from the output 3-phase voltages whose equations were explained in the previous section. Then, from the obtained instantaneous components, sampling is taken place. Since the controlling system uses just Vq to control the STATCOM, a de-multiplexer is used to extract $\mathrm{Vq}$ voltage from $\mathrm{Vd}$ and $\mathrm{V} 0$. The obtained $\mathrm{Vq}$ is then entered as an input to the controlling function upon the MATLAB software. The controlling function generates the amount of conducting angle, needed for the GTOs of the STATCOM. A phase shifting block is designed to control the appropriate phase angle of the exerting pulses upon the GTOs of the STATCOM. The outputs of this unit are entered into the STATCOM as inputs.

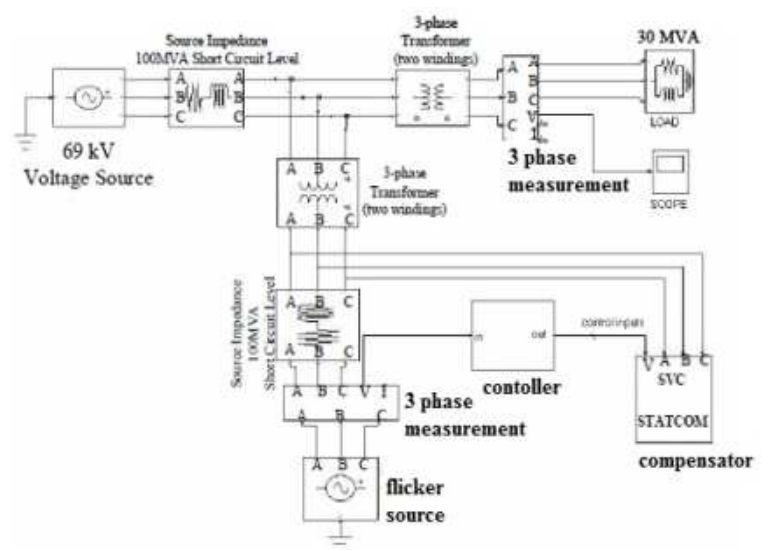

Fig 4.3. The studied power system

\section{Simulation and Analysis of the Results}

In order to investigate the influence of the STATCOM as an effective mitigating device for voltage flicker, three types of compensators are simulated in MATLAB. First, the voltage flicker compensation is adopted using FCTCR. Then a 6-pulse voltage-source converter STATCOM is used and finally for a complete voltage flicker mitigation a 12-pulse voltage-source converter STATCOM is designed. The compensation techniques and their results are presented in this section.

\subsubsection{Compensation Using FCTCR}

In this stage a FCTCR; one of the FACTS devices being controlled by a thyristor is used to mitigate the voltage flicking. In this case, the exerted voltage flicker into the system and the compensated voltage

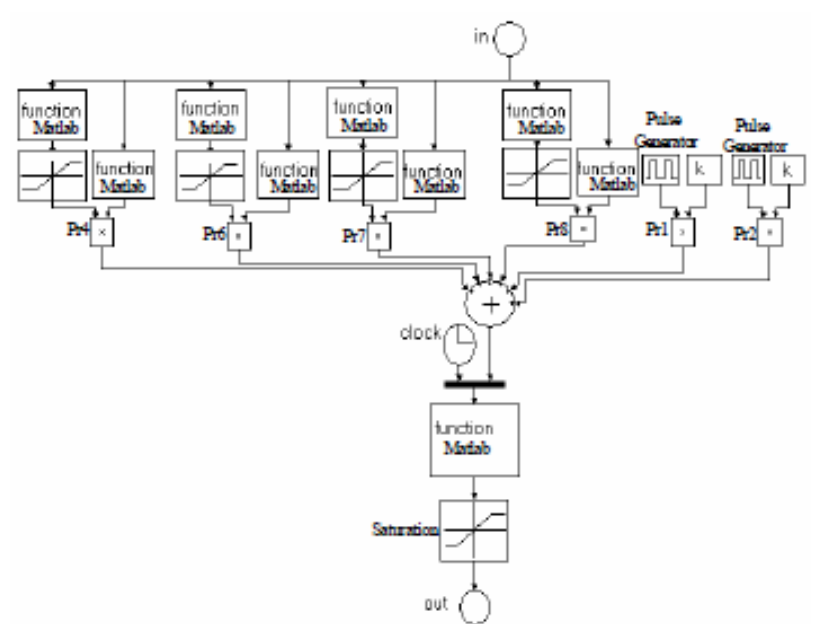

Fig4.4. Compensation using FCTCR

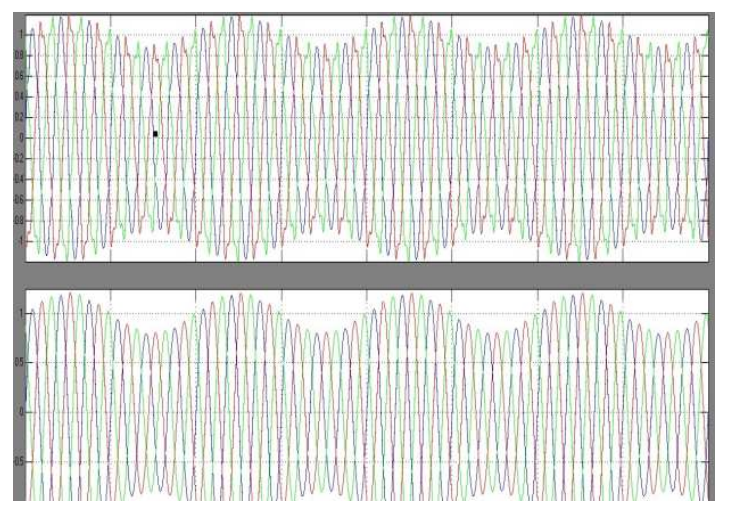

Fig 4.5. output for FCTCR

It is obvious from the output voltage waveform controlled by FCTCR that this technique achieves a reasonable level of mitigation but is incapable to be perfectly successful. Furthermore, in spite of using a snubber circuitto eliminate voltage spikes caused by the huge TCR reactor switching, there are still distortions in the output waveform.

\subsubsection{Compensation Using 6-pulse Voltage-source Converter STATCOM}

The circuit diagram of a three-phase 6-pulse voltage source converter STATCOM is shown in figure 5.6. Six valves compose the converter and each valve is made up of a GTO with a diode connected in anti-parallel. In this type of STATCOM, each GTO is fired and blocked one time per line voltage cycle. In this case, each GTO in a single branch is conducted during a half-cycle (180 degree) of the fundamental period. The combined pulses of each leg have a 120 degrees phase difference to produce a balanced set of voltages. By adjusting the conducting angle of the GTOs, the generated voltage and then the injected or absorbed power of the STATCOM are controlled. In this respect, the compensated output voltage by 6-pulse voltage-source converter STATCOM is presented in figure 5.12. 


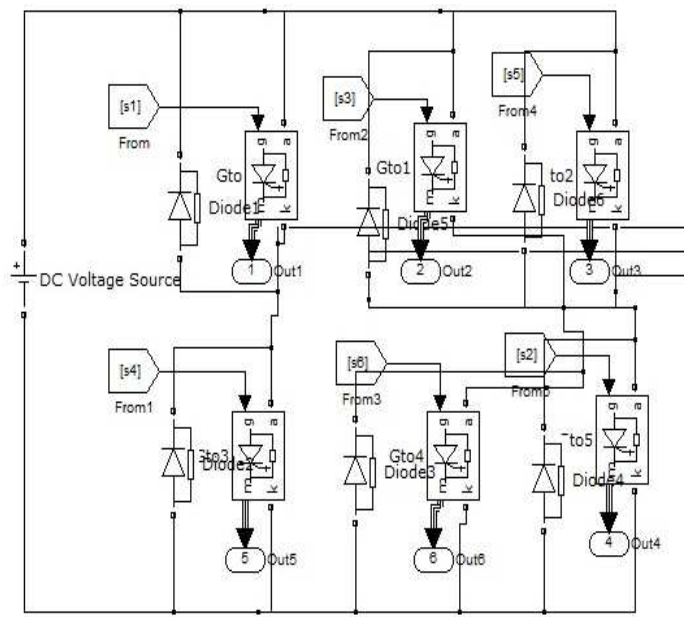

Fig 4.6. pulse VSI

\section{Controlling Unit}

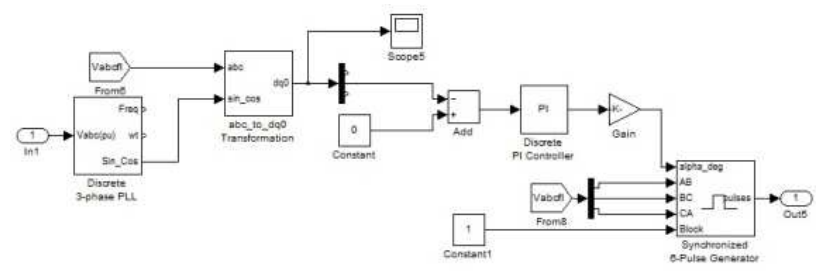

Fig 4.7. controlling block

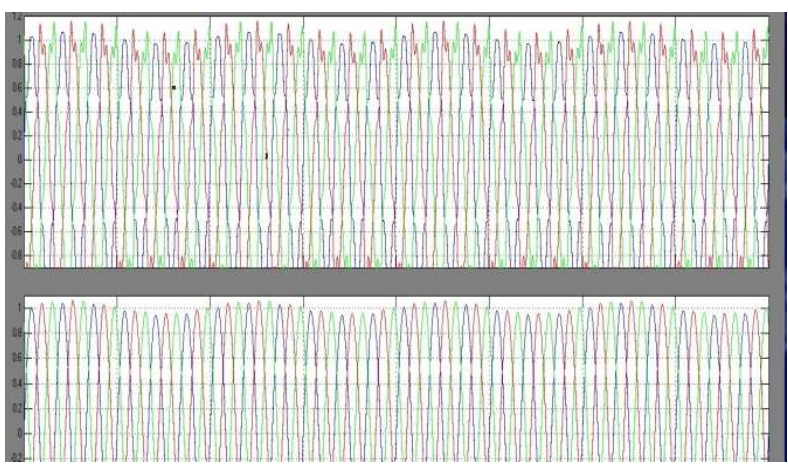

Fig 4.8. output of 6 pulse VSI

It can be seen that the mitigation effects of this compensator is better than that of FCTCR and effectively mitigate the voltage flicker; but the output voltage waveform has some considerable harmonics. The instantaneous output line-to-line voltage ( $\mathrm{Vab}$ ) of the 6pulse voltage-source converter is as follows

$$
V_{a b}=\sum_{n=1,3,5, \ldots}^{\infty} \frac{4 V_{s}}{n \pi} \cos \frac{n \pi}{6} \sin n\left(w t+\frac{\pi}{6}\right)
$$

As we see it is clearly perceptible from the above equation that, the even harmonics in the instantaneous line-to-line voltage has zero value and does not enter the network voltage. Connecting the voltage-source converter with a wye-delta transformer to the network, multiple 3rd Harmonics $(3,9,15 \ldots)$ are eliminated from the line voltages. Therefore, the considerable existing characteristic harmonics in the output voltage waveform in addition to the fundamental component are 5, 7, 11, 13 and higher whose values are shown in the harmonic spectrum of figure 9. It can be observed from the harmonic spectrum that 5 th and 7 th harmonics have considerable level comparing to the fundamental harmonics. Furthermore, 11th and 13th harmonics are considerable which should be eliminated from the network voltage waveforms. However, higher harmonics (namely 17th, 19th and above) have values very close to zero

\subsubsection{Compensation Using 12-pulse Voltage-source Converter Statcom}

In order to reduce the harmonic contents at the output voltage, the number of pulses can be increased, forming a multi-pulse configuration. Multi-pulse converters are composed by $n(n=2,4,8 \ldots)$, where $n$ is the number of pulses. 6-pulse bridges connected in parallel on the same DC bus and interconnected in series through transformers on the AC side. Depending on the number of pulses, these transformers and their connections can become very complex.

Two 6-pulse bridges are connected, forming a 12-pulse converter for a complete voltage flicker compensation design. In this case, the first converter is connected with a wye-wye transformer and the second one with a wye-delta transformer. These are linked together using a three winding transformer. Moreover, the delta-connected secondary of the second transformer must have 3 times the turns compared to the wye-connected secondary and the pulse train to one converter is shifted by 30 degrees with respect to the other. The 12-pulse voltage-source converter STATCOM circuit diagram is shown in figure 4.10

\section{Pulse generating Unit}

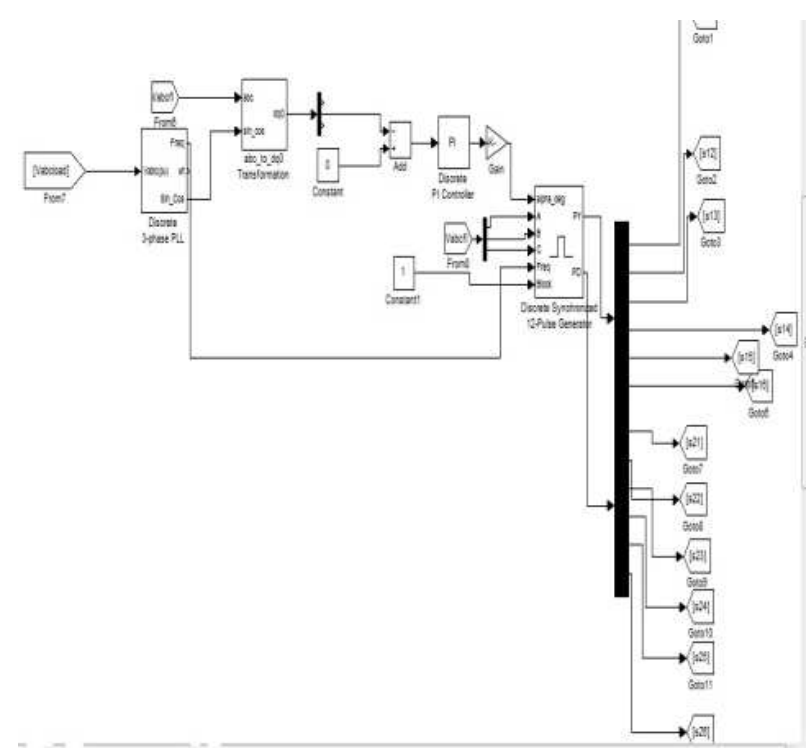

Fig 4.9 pulse generating unit 


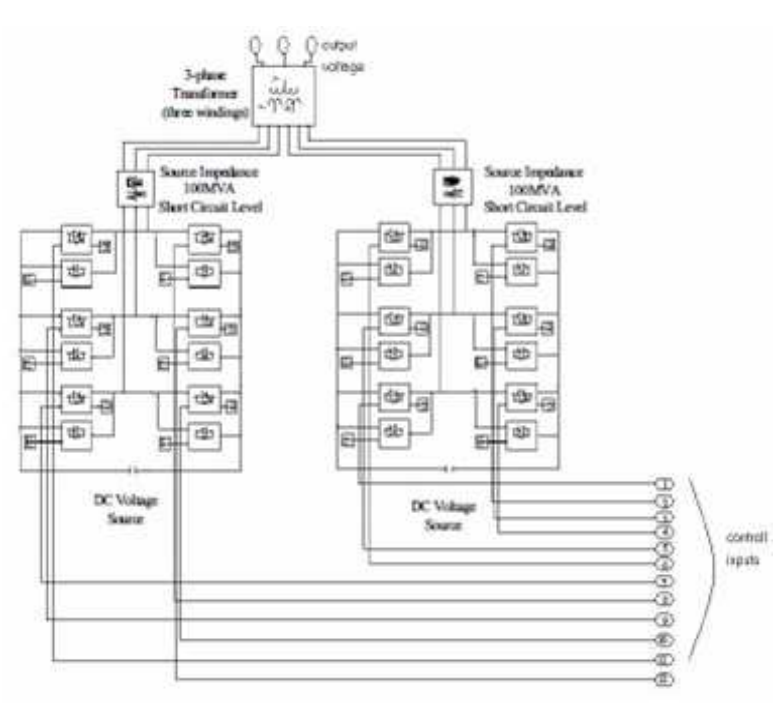

Fig 4.1012 pulse VSI

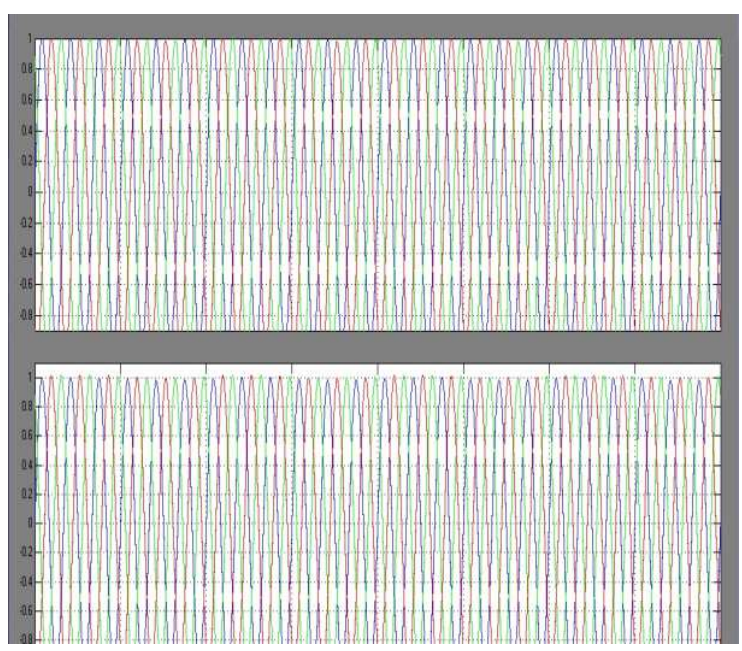

Fig4.11. output of 12 pulse

The complete STATCOM control system scheme is implemented on the power system introduced. The output voltage mitigated by 12-pulse voltage-source converter STATCOM and its harmonic spectrum are depicted in figures 11 and 12 respectively. In this respect, the voltage flicker is completely removed from the output voltage and a sinusoidal waveform is obtained. Furthermore, it is clearly obvious (from the harmonic spectrum) that almost all harmonics are removed from the output voltage. The only injected harmonics to the system are 11 and 13 that are deleted adding an RLC active filter to the designed compensator.

Table 4.1 for total harmonic distortion

\begin{tabular}{ll}
\hline model & total harmonic distortion $(\%)$ \\
\hline fctcr & $8.03 \%$ \\
6 pulse statcom & $5.47 \%$ \\
12 pulse statcom & $1.33 \%$ \\
\hline
\end{tabular}

\section{Conclusions}

The design and application of STATCOM technology based on voltage-source converters for voltage flicker mitigation is discussed in this paper. Mitigation is done in three stages and the results are compared and contrasted. First, FCTCR is used to compensate for the voltage flicker, then a 6pulse voltage-source converter STATCOM and finally a 12pulse STATCOM based on voltage-source converter equipped with an RLC filter are designed for complete voltage flicker compensation without harmonics. All the simulated results which have been performed in

MATLAB show that a 6-pulse STATCOM is efficiently effective in decreasing the voltage flicker of the generating loads. However, there is injection of the harmonic from STATCOM into the system which can be improved with the increase of the voltage source converters of STATCOM using a 12-pulse STATCOM equipped with an RLC filter. The obtained results clearly demonstrate that 12-pulse STATCOM equipped with an RLC filter can reduce the voltage flicker caused by nonlinear loads such as electric arc furnaces.

\section{Acknowledgements}

I Thank to our Institute Executive directors Mr.T Sai kumar \&Mr.D Baba for providing creative environment for this work. Also I am very much thankful to our Institute principal Dr. K Ramesh for his kind permission and encouragement to write research paper. I would like to extend my heartfelt thanks to my colleagues. And finally I am very much obliged to my respected parents who inspiring me around the clock.

\section{References}

[1] J. Sun, D. Czarkowski, Z. Zabar, "Voltage Flicker Mitigation Using PWM-Based Distribution STATCOM", IEEE Power Engineering Society Summer Meeting, Vol.1, (21-25 July 2002), pp. 616-621.

[2] J. Mckim, "The UIE Flicker-meter Demystified", HewlettPackard's Power Products Division, 1997.

[3] R. Collantes-Bellido, T. Gomez, "Identification and Modeling of a Three Phase Arc Furnace for Voltage Distribution Simulation", IEEE Trans. on Power Delivery; Vol.12, No.4, (1997), pp. 1812-1817.

[4] L. Tang, S. Kolluri, M.F. McGranaghan, "Voltage Flicker Prediction for Two Simultaneously Operated AC Arc Furnaces" IEEE Trans. on Power Delivery; Vol.12, No.2, (1997), pp. 985-991.

[5] M. Zouiti, S. Saadate, X. Lombard, C. Poumarede, C. Levillain, "Electronic Based Equipment for Flicker Mitigation", Proceedings of International Conference on Harmonics And Quality of Power, Vol.2, (1998), pp. 1182-1187. 
[6] T. Larsson, C. Poumarede, "STATCOM, an efficient means for flicker mitigation" IEEE Power Engineering Society Winter Meeting, Vol.2, (Jan-4Feb 1999), pp. 1208-1213.

[7] C. S. Chen, H. J. Chuang, C. T. Hsu, S. M. Tscng, "Stochastic Voltage Flicker Analysis and Its Mitigation for Steel Industrial Power Systems", IEEE Power Tech Proceedings, Vol.1, (10-13 Sept. 2001).

[8] Z. Zhang, N. R. Fahmi, W. T. Norris, "Flicker Analysis and Methods for Electric Arc Furnace Flicker (EAF) Mitigation (A Survey)", IEEE Power Tech Proceedings, Vol.1, (10-13 Sept. 2001).

[9] J. R. Clouston, J. H. Gurney, "Field Demonstration of a Distribution Static Compensator Used to Mitigate Voltage Flicker", IEEE Power Engineering Society Winter Meeting, Vol.2, (31 Jan-4 Feb 1999), pp. 1138- 1141.

[10] Elnady, W. El-khattam, M. A. Salama, "Mitigation of AC Arc Furnace Voltage Flicker Using the Unified Power Quality Conditioner", IEEE Power Engineering Society Winter Meeting, Vol.2, (27-31 Jan. 2002), pp. 735-739.

[11] S. Suzuki, Y. Hara, E. Masada, M. Miyatake, K. Shutoh, "Application of Unified Flow Controller for Power Quality Control at Demand Side", The Third International Power Electronics and Motion Control Conference Proceedings (PIEMC 2000), Vol.3 (15- 18Aug 2000), pp. 1031-1036.

[12] Y. Hara, E. Masada, M. Miyatake, K. Shutoh, "Application of Unified Flow Controller for Improvement of Power Quality" IEEE Power Engineering Society Winter Meeting, Vol.4, (23-27 Jan. 2000), pp. 2600-2606.

[13] J. H. R. Enslin, "Unified Approach to Power Quality Mitigation" International Symposium on Industrial Electronics (ISIE '98), IEEE Proceedings, Vol.1, (July1998), pp. 8-20.

[14] P. Roberts, "Power Quality Solution Alternatives for Low and Medium Voltage Continuous Process Loads", IEEE Rural Electric Power Conference, (5-7 May 2002), pp. C4-C4_7.

[15] G. C. Montanari, M. Loggini, L. Pitti, E. Tironi, D. Zaninelli, "The effects of series inductors for flicker reduction in electric power systems supplying arc furnaces", IEEE Industry Applications Society Annual Meeting, Vol.2, (2-8 Oct. 1993), pp.1496-1503.

[16] M. W. Marshall, "sing Series Capacitors to Mitigate Voltage Flicker Problems" IEEE Rural Electric Power Conference, (20-22 April 1997), pp. B3-1-5.

[17] J. Dolezal, A. G. Castillo, V. Valouch, "Topologies and control of active filters for flicker compensation", International Symposium on Industrial Electronics, IEEE Proceedings, Vol.1, (4-8 Dec, 2000), pp. 90-95.

[18] L. Gyugi, A. A. Otto, "Static Shunt Compensation for Voltage Flicker Reduction and Power Factor Correction", American Power Conference (1976), pp. 1272-1286.

[19] Y. Hamachi, M. Takeda, "Voltage Fluctuation Suppressing System Using Thyristor Controlled Capacitors", 8th U.I.E. Congress, (1976).

[20] F. Frank, S. Ivner, "TYCAP, Power Factor Correction Equipment Using Thyristor Controlled Capacitor for Arc Furnaces", ASEA Journal, No.46, Vol.6, (1973) pp. 147-152.

[21] R. Mienski, R. Pawelek, I. Wasiak "Shunt Compensation for Power Quality Improvement using a STATCOM controller: Modelling and simulation", IEE Proc.-Gener. Transm. Distrib., No.2, Vol.151, (2004), pp. 274-280.

[22] Amit K. Jain, AmanBehal, Ximing, Darren M. Dawson, Ned Mohan "Nonlinear Controller for Fast Voltage Regulation Using STATCOMs" IEEE Transaction. On control systems technology, No.6, Vol.12, (2004), pp. 827-842.

[23] Math Works Company, 'Manual for MATLAB Simulink Software, User's Guide', 2002, Version 6.5.

[24] H. Akagi, Y. Kanazawa, A. Nabae, "Instantaneous Reactive Power Compensator Comprising Switching Devices Without Energy Storage Components", IEEE Trans. on Industry Applications, No.3, Vol.20, (1984), pp. 625-630.

[25] Castagnet, T., 'Is the Snubber Circuit Necessary?', STMicroelectronics, Group of Companies, Application Notes, Printed in Italy, 1999. 